\title{
ESTUDIO DE DENUDACIÓN EN PIROCLASTOS TIERRA BLANCA JOVEN DENTRO EL ÁREA METROPOLITANA DE SAN SALVADOR
}

\author{
DENUDATION STUDY IN TIERRA BLANCA JOVEN PYROCLASTS WITHIN THE \\ METROPOLITAN AREA OF SAN SALVADOR
}

\author{
Mauricio E. Vásquez, José A. Chavez* y Fabio E. Gracias \\ Oficina de Planificación del Área Metropolitana de San Salvador (OPAMSS) \\ *Autor para contacto: alex.chavez@opamss.org.sv
}

(Recibido: 02/02/2017; aceptado: 24/05/2017)

\begin{abstract}
Severe problems of denudation are happening in Tierra Blanca Joven pyroclasts within the Metropolitan Area of San Salvador, affecting infrastructure and housing projects. This leads to necessary and constant mitigation works. To understand the behavior and characteristics of these pyroclasts a monitoring program began. This was made through the installation in some sectors of $3 / 8$ inch rods to recognize changes of erosion and sedimentation. With the help of remote sensors, historical changes were identified in the drainages. For this area a map of erodibility with the Universal Equation of Soil Loss was obtained. The results show the importance and influence of climatic factors, tectonic, human actions and changes of the base level of drainage. This can be used to build criteria for research and propose protection zones in the river drainage system. The monitoring probes to be useful and is necessary to improve it.

Keywords: pyroclasts, erosion, landslide, monitoring, remote sensor, gully.

RESUMEN: Problemas severos de denudación se observan en los piroclastos Tierra Blanca Joven dentro del Área Metropolitana de San Salvador, afectando infraestructura y proyectos urbanísticos. Esto conlleva a que sean necesarias obras de mitigación de manera constante. Para conocer el comportamiento y características de este material, se inicio un monitoreo por reconocimiento de cambios de erosión y sedimentación, instalando en algunos sectores de la cuenca del Río las Cañas varillas de 3/8 de pulgadas. Con la ayuda de sensores remotos se identificaron cambios históricos en los drenajes. Para esta zona se obtuvo un mapa de susceptibilidad de erosión con la Ecuación Universal de la Perdida de Suelo. Los resultados muestran la importancia e influencia de factores climáticos, tectónicos, acciones antrópicas y cambios del nivel base de los drenajes. Esto puede servir para criterios de estudios y zonas de protección. El monitoreo probo ser una herramienta útil que tiene que ser reforzada.
\end{abstract}

Palabras clave: piroclastos, erosión, movimientos de ladera, monitoreo, sensor remoto, cárcava. 


\section{INTRODUCCIÓN}

La erosión fluvial a lo largo de la historia ha sido una problemática que se ha tratado de mitigar y conocer con diferentes técnicas o metodologías, inicialmente dándose mayor énfasis para la agricultura. Pero también, los ríos y quebradas contienen vida acuática y los ecosistemas que se ven trastornados debido a las cantidades de sedimento transportado por la erosión. La depositación de material o sedimentos trasportados por los drenajes puede reducir también la capacidad de almacenamiento y vida útil de presas hidroeléctricas o reservorios, así como, incrementar el riesgo de inundaciones aguas abajo debido a cambios en la forma o tipo de canal y curso del drenaje, existiendo zonas de erosión y acumulación en las llanuras aluviales (Chavez et al., 2014a).

Todo lo mencionado anteriormente, más la problemática de daños a obras civiles y su constante mitigación que ocurre por los procesos de denudación hace que sea básico el estudio de los procesos erosivos para comprender la problemática y mejorar la toma de decisiones apropiadas.

Entre las metodologías e investigaciones a nivel internacional, hay bastantes experiencias entre las que la destaca la del método de Ecuación Universal de la Perdida de Suelo (USLE) de Wischmeier y Smith (1978) ya que fue unos de los primeros intentos de tener criterios con respecto a la erosión, para la conservación y planificación del territorio.

Otras investigaciones de Lee (2004); Kheir et al. (2006); Vrieling (2006); Malik (2008); Griffiths y Stokes (2008); Vrieling et al. (2008); Perroy et al. (2010); Nigel y Rughooputh (2010); Martín-Fernández y Martínez-Núñez (2011); Chiu et al. (2011); de Oliveira et al. (2011); James et al. (2012); Vergari (2015); Jiang et al. (2015); Aucelli et al. (2016) aplican, retoman, y proponen otras metodologías para el estudio y mapeo de la erosión. Yang y Zhu (2003) explican que para el estudio de la erosión se usan actualmente los sensores remotos y los Sistemas de Información Geográfica (GIS) y que se dividen en la interpretación visual, análisis espectrales, determinación de parámetros, así como la interpretación interactiva con criterios de experto y de computadora.
En el Área Metropolitana de San Salvador (AMSS) la erosión fluvial es la que tiene mayor impacto e importancia, debido a eso es que en este estudio se le ha dado mayor relevancia. Los procesos de erosión fluvial incluyen tanto el desprendimiento, arrastre, transporte y depósito del material.

La problemática de erosión a nivel local ha sido estudiada por Escobar et al. (1986); Baxter (1995); Kim et al. (2005); Šebesta et al. (2010); Šebesta y Chavez (2011); Chavez et al. (2012); Chavez et al. (2014a) las cuales se han centrado en su mayoría en el Área Metropolitana de San Salvador (AMSS) con especial énfasis en la cuenca del río Cañas. Identificándose como un material especialmente problemático a la denudación (Chavez et al., 2012, 2014a) los piroclastos Tierra Blanca Joven (TBJ) debido a sus propiedades y características. Las Áreas Metropolitanas son las zonas donde se concentra la mayor actividad económica, y por consiguiente mayor concentración poblacional, lo que implica un aumento en la demanda de vivienda, infraestructura, servicios básicos, y aperturas de infraestructuras viales. Esto hace que en zonas urbanizadas cerca de ríos y quebradas, al desconocer su dinámica se construya sin mayor restricción y puedan ser zonas susceptibles a problemas de erosión, inundación y movimientos de ladera.

La presente investigación trata de caracterizar el comportamiento de suelos piroclásticos erosivos, desde un enfoque teórico-práctico, teniendo como área de investigación la cuenca del río Las Cañas en El Salvador, que es donde se concentran importantes espesores de piroclastos recientes (esto por su proximidad a la Caldera de Ilopango); siendo esta cuenca un territorio fuertemente impactado por problemas de denudación (movimientos de ladera y erosión).

Entre la metodología usada se puede mencionar el uso de la Ecuación Universal de la Perdida de Suelo (USLE) (Wischmeier y Smith, 1978) por medio de ArcGIS, para el cálculo de pérdida de suelo; la utilización de sensores remotos de los años 1949, 1984, 2007 y 2012, así como de Google Earth de los años 2002 a 2015, con los cuales se ha construido una tendencia horizontal del comportamiento de los ríos y quebradas 
en un intervalo de tiempo de 67 años (de 1949 a 2015). Así mismo, se ha realizado el monitoreo en campo de puntos estratégicos de taludes, cárcavas, riberas de ríos y quebradas, lechos de cauces con mediciones de la tasa de erosión presentados durante el período lluvioso de 2015. También se ha utilizado información cartográfica geológica y geomorfológica. Uno de los resultados que se busca con la investigación es tener criterios y estudios necesarios para la demarcación de las zonas de protección de ríos y quebradas donde la problemática es intensa.

\section{Área de estudio}

El río Las Cañas se ubica al Oriente del AMSS (Fig. 1). La superficie de la zona de estudio es de $73,85 \mathrm{~km} 2$; con un $25,84 \%$ de suelo ocupado por tejido urbano, $25,38 \%$ con cultivos, pastos y granos básicos, 22,81\% vegetación arbórea, sumando alrededor del $74 \%$ del total del área; el restante $26 \%$ presenta usos varios (MARN, 2013)

Los materiales de la TBJ están conformados por depósitos piroclásticos de caída, flujos piroclásticos (ignimbritas) y depósitos de oleadas piroclásticas (surge). Según Hernández (2004) la TBJ es clasificada en nueve unidades estratigráficas de la "A" hasta la " $G$ ", incluyendo las ignimbritas alfa e ignimbritas beta; siendo la unidad $\mathrm{E}$ el estrato guía que a veces ayuda a identificar y clasificar los estratos de TBJ en campo. Dentro del territorio del AMSS los espesores más importantes son los de la unidad "F" (Chavez et al., 2012, Fig. 2).

Todos los autores caracterizan a los piroclastos TBJ (Chavez et al., 2012) como arenas limosas y limos arenosos, concluyéndose que son colapsables y que hay una disminución de la resistencia al corte al saturarse o debido a terremotos/ vibraciones, si se compara con una muestra de humedad natural. Debido a que son suelos parcialmente saturados (presencia de agua, aire y suelo) es necesario caracterizarlos basados en modelos constitutivos que tomen en cuenta la succión o con la ayuda de la Curva de Retención SucciónAgua (Chavez et al., 2013, 2014b, 2016)

Por otra parte según el mapa Geomorfológico del AMSS (Šebesta y Chavez, 2011) en la parte alta de la cuenca de las Cañas predominan los Badlands (Área de Erosión Densa Contemporánea), Llanuras Aluviales, Fallas Geológicas y Superficies Estructurales de la Caldera. La parte media y baja de la cuenca, cuenta con Relieve Policíclico sobre restos de Formación Bálsamo, Ladera de Erosión o Denudación, Llanuras Aluviales, Fallas Geológicas y Superficies Estructurales de la Caldera (Erosionadas) (Fig. 2).

Los Badlands se originan en los depósitos de caída y flujos piroclásticos de TBJ, donde la erosión planar, de surcos y barrancos es común e intensa; siendo la susceptibilidad a los movimientos de ladera muy alta. Según Šebesta et al. (2010) y Chavez et al. (2012) la combinación del cambio de nivel base; los cambios antropogénicos (urbanizaciones, deforestación, extracción de arena, como es el caso del río Las Cañas); el clima (sequia, huracanes o depresiones tropicales) y la tectónica (se puede observar fallamiento intenso en TBJ) son los principales controles externos de las altas tasas de erosión en la zona proximal de la Caldera de Ilopango, que afecta a la morfología y a infraestructura civil cercana a ríos y quebradas.

Normalmente se observa en la zona, taludes verticales sin cobertura vegetal en parte frontal, ampliación de las secciones transversales de los ríos y quebradas, surgimiento de cárcavas o barrancos y problemas de colapso de infraestructura urbana (Fig. 3). Procesos que muestran gran intensidad y conllevan a inversiones millonarias en términos de reparación de obras de paso, pero debido a desconocimiento de la dinámica fluvial las soluciones propuestas son a corto plazo y al poco tiempo requieren de mejoras en sus diseños o la afección se traslade a otros sectores de la cuenca.

Es de resaltar que si bien es cierto que en los últimos años se ha incrementado la problemática de los piroclastos TBJ, en la década de los $80^{\prime}$ s estos suelos en la cuenca del río Cañas ya presentaban una dinámica erosiva acelerada. Escobar et al. (1986) ya enfatizaba como la concentración de las aguas de drenaje y crecidas durante inundaciones, agravaba el problema. Esto hizo que los índices de erosión se catalogaran como una amenaza a pesar de que en ese entonces la parte alta de la cuenca estaba cubierta en su ma- 


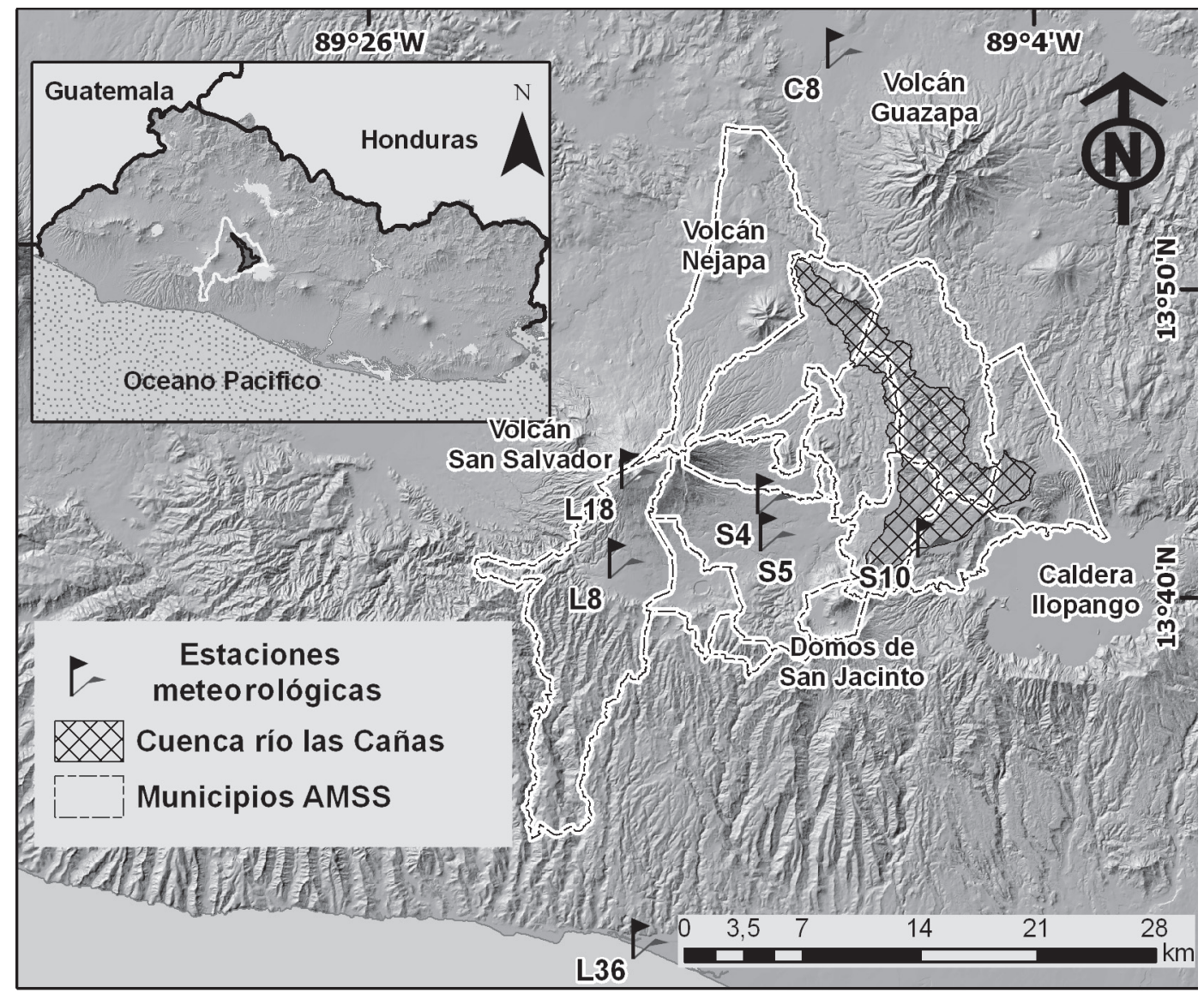

Fig. 1: Ubicación de la zona de estudio y estaciones meteorológicas. Estaciones meteorológicas de Ilopango (S10), Boquerón (L18), Observatorio (S5), Santa Tecla (L8), ITIC (S4), Aguilares (C8) y San Diego (L-36)

yoría por plantaciones de caña de azúcar, cereales, bosques, pasto natural, matorral, café y tabaco; así como algunos desarrollos urbanos (Escobar et al., 1986).

Baxter (1995), explica que la dinámica del río Las Cañas está estrechamente vinculada al desarrollo de un valle, ya que se ha formado por la acción de tres procesos: profundización (acción hidráulica), ensanchamiento (erosión lateral) y alargamiento (erosión retrograda, aumento de meandros, cambios de nivel de base). Una vez se iniciaron en los años 60's los fenómenos erosivos, la pendiente suave fue reemplazada por taludes verticales, superando en algunos casos varios metros de altura.

\section{METODOLOGÍA Y RESULTADOS}

A continuación se presentan los análisis realizados para la cuenca del río Las Cañas con el fin de conocer la problemática de denudación, determinar la tasa potencial de erosión y construcción de criterios para propuesta de zona de protección.

\section{Uso de sensores remotos}

Para mostrar los cambios de márgenes de los ríos y quebradas que conforman la cuenca del río Las Cañas, se contó con fotografías aéreas e imágenes satelitales de los años: 1949, 1984, 2007 y 2012, 


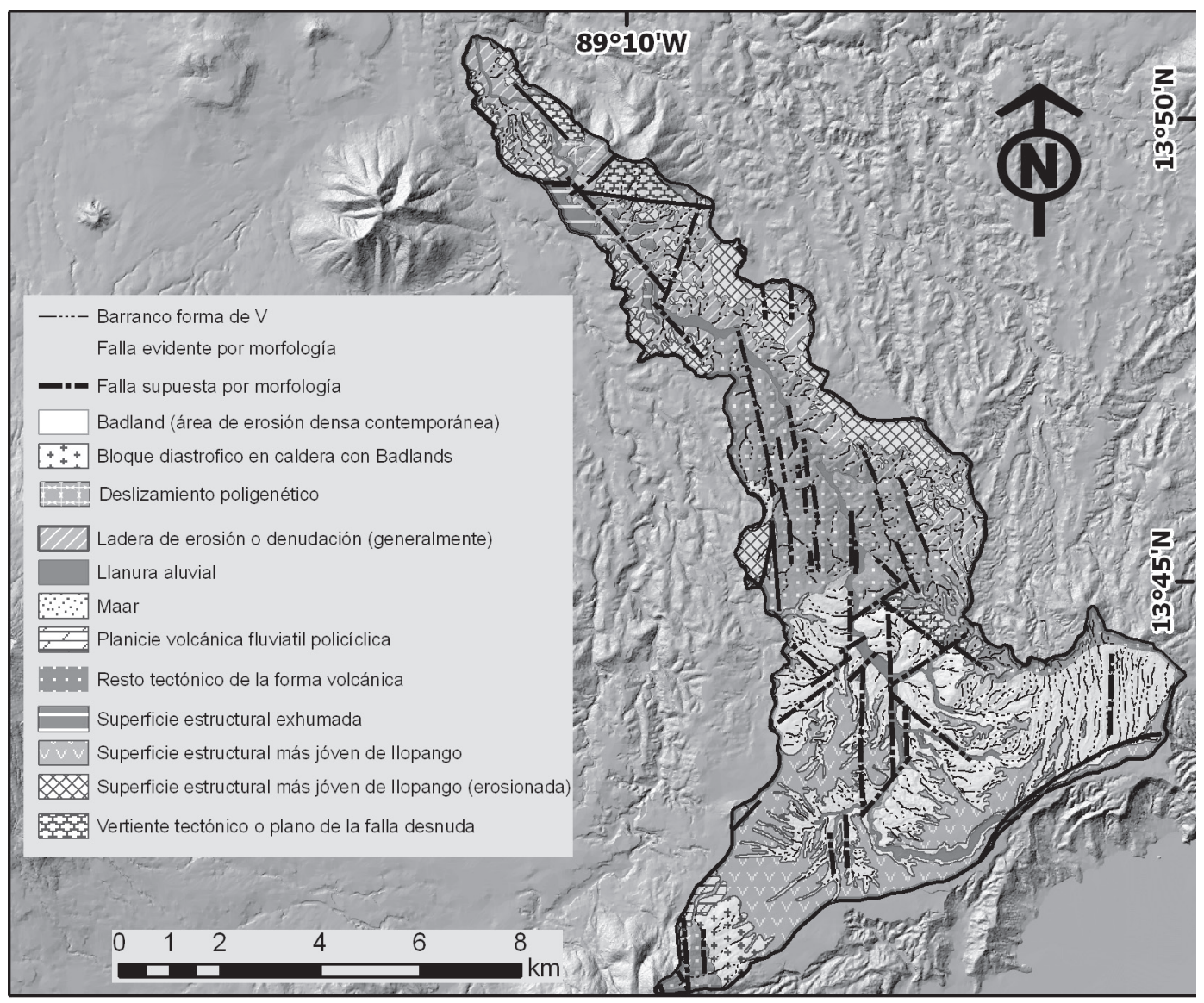

Fig. 2: Mapa Geomorfológico del AMSS (Šebesta \& Chavez, 2011).

además de la cobertura de imágenes que nos provee la herramienta Google Earth desde el año 2002 a la fecha. Se analizaron los cambios geomorfológicos de los cauces de sector de las Cañas, con la limitación que este solo se puede realizar con vista en planta, pero que brinda una tendencia de movimiento en un periodo de 67 años, a partir de 1949.

En la figura 4 se muestra la dinámica geomorfológica de los diferentes márgenes por año, que corresponde a la parte alta de la cuenca río Las Cañas. Al hacer comparaciones de las tendencias de los cambios horizontales en los periodos de lluvia entre 2002 y 2015 se identificó que los cauces principales se ampliaron anualmente $5 \mathrm{~m}$ en promedio.

\section{Puntos de monitoreo de erosión}

Para contrastar la problemática de la erosión en la zona y verificar resultados del mapa USLE elaborado, se decidió contar con datos de erosión in situ, durante el periodo lluvioso del 2015. Para la toma de lecturas se identificó en la zona proximal de la caldera de Ilopango taludes, cárcavas y lechos de quebradas que presentaban mayor susceptibilidad a erosión. Para tomar las mediciones de erosión en campo se utilizó método de reconocimiento (Hudson, 1997) lo cual consiste en la colocación de varillas de $3 / 8$ de pulgadas con una longitud no mayor a 40 centímetros, los cuales sirven para determinar desplazamientos 



Fig. 3: Problemas de denudación y situación de laderas de los ríos y quebradas. En (a) y (d) se muestra erosión retrograda en obras de paso.

horizontales y verticales que tengan las superficie de estos suelos con el trascurso del tiempo. Adicionalmente se utilizaron técnicas de topografía y de trazo en obra para poder tener valores de mediciones lo más ajustado a la realidad.

Los datos recolectados de las mediciones en campo se procesaron en una matriz creada a través de hola electrónica (Excel), desarrollando comparaciones entre el antes y después del periodo de control. En figura 5 se muestra el mapa de los puntos de monitoreo y su ubicación respecto a la cuenca del río Las Cañas. En el cuadro 1 se detallan los valores finales de erosión horizontal y vertical de todos los puntos monitoreados. A continuación, se presenta información de algunos de los puntos más destacados, con los cambios verticales y horizontales registrados durante el periodo de monitoreo.

\section{Cárcava en carretera Panamericana (punto 1 de Fig. 5)}

La erosión corresponde a descarga de aguas lluvias de carretera que ingresa e infiltra en terreno cultivado con maíz (Fig. 6 y cuadro 2). Al observar comportamiento y afectación se identificó que la erosión principalmente es subterránea y retrograda, lo que provoca un retroceso acelerado de su cabecera $(9,70 \mathrm{~m}$ y azolvamiento en su lecho).

\section{Taludes ribereños Qda. Arenal Seco; ubicado en la zona Franca San Bartolo (punto 5 de Fig. 5)}

Se trata de un tramo de la quebrada Arenal Seco de aproximadamente 50 metros de longitud, en donde se midió la erosión lateral y vertical (Fig. 3a). En el sector se reconstruyó en 2013 una obra de paso (con blindaje al cambio climático), ya que en 2012 colapso por la erosión retrógrada (Chavez et al., 2012, 2014a). Ya en Noviembre del 2015, la obra de paso estaba afectada nuevamente por erosión retrógrada (Fig. 7). En la Fig. 8 se muestra la distribución de pines en el punto 5 y erosión lateral.

En la Figura 9 se presentan los cambios en la profundización y ensanchamiento del cauce aguas abajo del punto de monitoreo. 


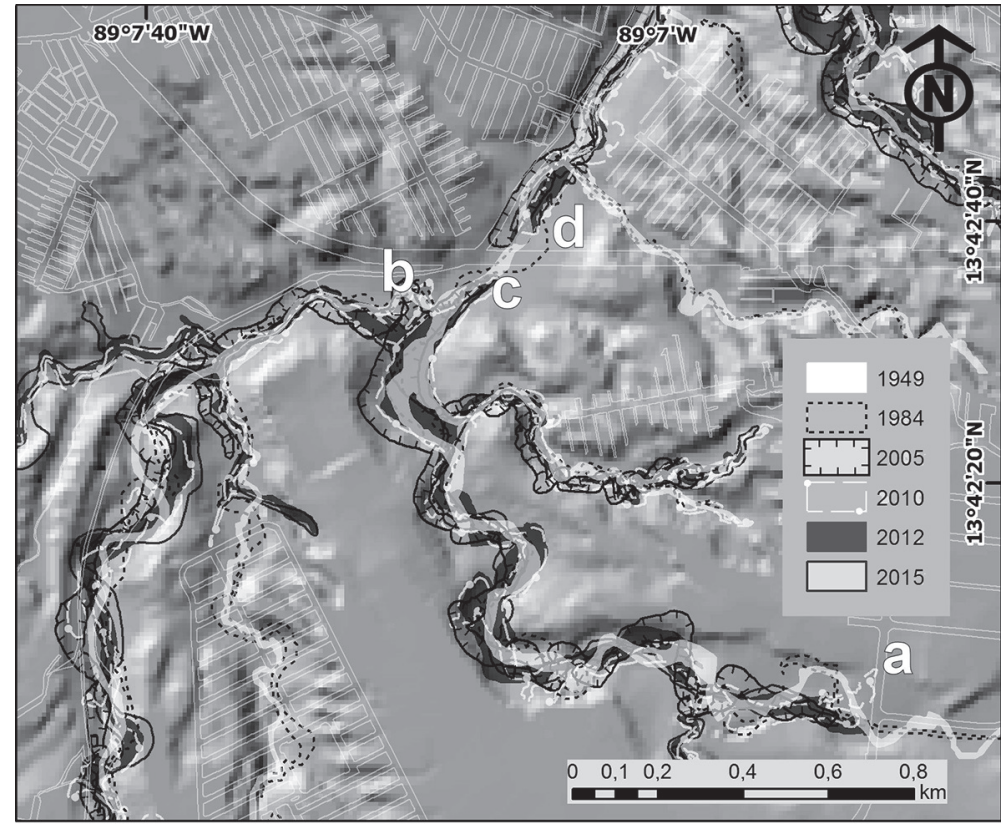

Fig. 4: Cambios geomorfológicos por año, que corresponden a la parte alta de la cuenca río Las Cañas. Se señalan puntos de ubicación de Fig. 3.

\section{Cuadro 1}

Desplazamientos promedios acumulados de cada punto monitoreado. (+ Erosión y - azolvamiento) según Fig. 5. OPAMSS: Oficina de Planificación del Área Metropolitana de San salvador y UES: Universidad del El Salvador.

\begin{tabular}{|c|c|c|c|c|}
\hline \multirow{2}{*}{$\begin{array}{l}\text { Descripción de puntos de } \\
\text { monitoreo }\end{array}$} & \multirow[t]{2}{*}{ Monitoreo } & \multicolumn{2}{|c|}{ Desplazamiento Vertical (mm) Acumulado } & \multirow{2}{*}{$\begin{array}{c}\text { Desplazamiento } \\
\text { Horizontal (mm) } \\
\text { Acumulado } \\
\text { Erosión }\end{array}$} \\
\hline & & Erosión & Azolvado & \\
\hline 1. Cárcava Carretera Panamericana & OPAMSS & - & $-1653,33$ & 4146,67 \\
\hline 2. Cárcava Vía Galicia I & OPAMSS & 165 & $-510,00$ & 726,67 \\
\hline 3. Lecho de Cauce & OPAMSS & - & $-513,50$ & - \\
\hline 4. Obra de Descarga Texaco & OPAMSS & 403,00 & $-132,50$ & - \\
\hline 5. Talud Zona Franca & OPAMSS & 2180,00 & - & 7563,33 \\
\hline 6. Talud Padre Arrupe & OPAMSS & 3,5 & - & 2,57 \\
\hline 7. Talud Via Galicia & UES & - & 640 & 380 \\
\hline 8. Talud Arrupe I & UES & 61,3 & -20 & - \\
\hline 9. Talud Arrupe II & UES & 11,8 & $-32,4$ & - \\
\hline 10. Talud Cipreses I & UES & 522 & -370 & 945 \\
\hline 11. Talud Cipreses II & UES & 605 & -210 & 2385 \\
\hline 12. Talud Zona Franca I & UES & 1512,5 & - & 10260 \\
\hline 13. Sección Cauce Zona Franca II & UES & 2550 & -2150 & 5800 \\
\hline 14. Talud UES & UES & 9,31 & 17,43 & - \\
\hline
\end{tabular}




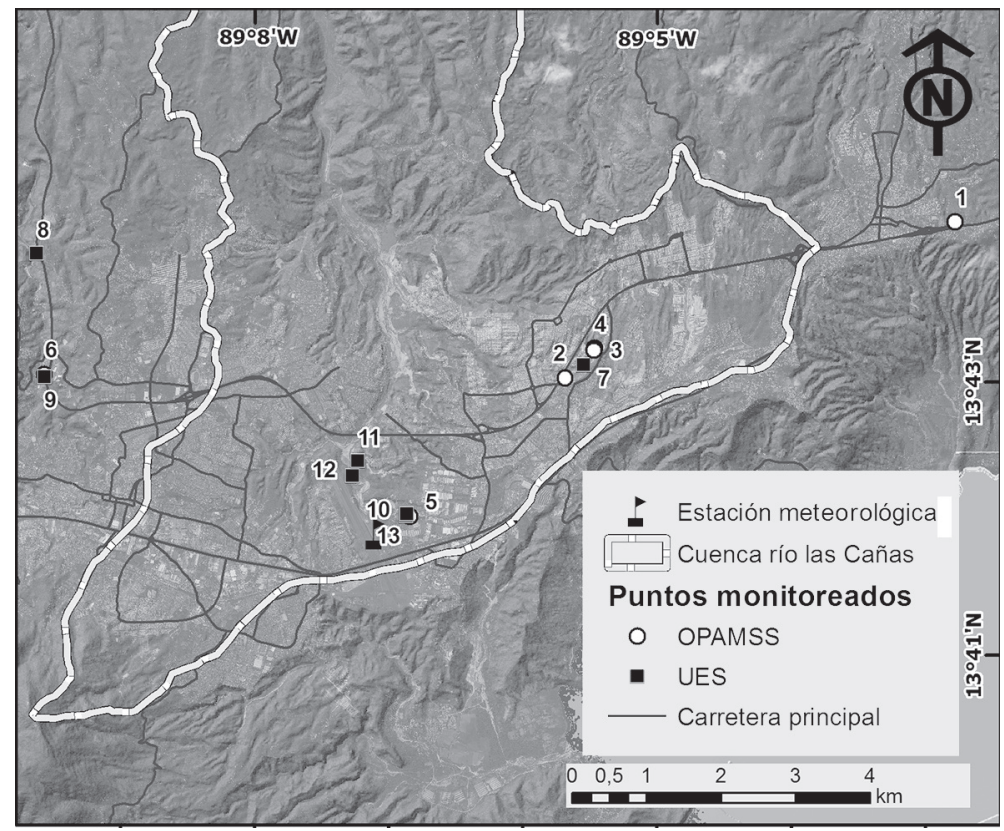

Fig. 5: Puntos de monitoreo y su ubicación respecto a la cuenca del río Las Cañas. OPAMSS: Oficina de Planificación del Área Metropolitana de San salvador y UES: Universidad del El Salvador

Para los puntos de monitoreo 1 y 5 de la figura 5 ocurrió profundización de cauce, con la diferencia que en el caso del punto 1 de punto 5 este presentó azolvamiento vertical a medida se erosionaba lateralmente, por causa del material acumulado en el fondo y que no es arrastrado por la escorrentía; en el caso de erosión lateral ambos casos siguieron la tendencia al aumento. A continuación se presentan el análisis comparativo de resultados de punto 1 y 5 en figura 10, en donde se superponen a los datos de lluvia del año 2015 de la estación de Ilopango.

\section{Comportamiento Erosión en lecho de cauce} tributario a Quebrada las Pavas (punto 3 de Fig. 5)

Para conocer el comportamiento de azolvamiento y erosión en el lecho de quebrada se colocaron seis puntos de control de erosión y sedimentación en una sección. Es de destacar que no se presentaron cambios horizontales durante el monitoreo, solo cambios verticales. En la figura 11 el signo positivo denota procesos de erosión y los negativos de azolvamiento.

Cuadro 2

Datos finales del monitoreo para la cárcava Panamericana.

\begin{tabular}{ccccc}
\hline Tipo de Desplazamiento & Punto 1 & Punto 2 & Punto 3 & Comportamiento \\
\hline Vertical $(\mathrm{m})$ & $-1,32$ & $-2,32$ & $-1,32$ & Azolvamiento \\
Horizontal $(\mathrm{m})$ & 1,89 & 9,7 & 0,85 & Erosión \\
\hline
\end{tabular}




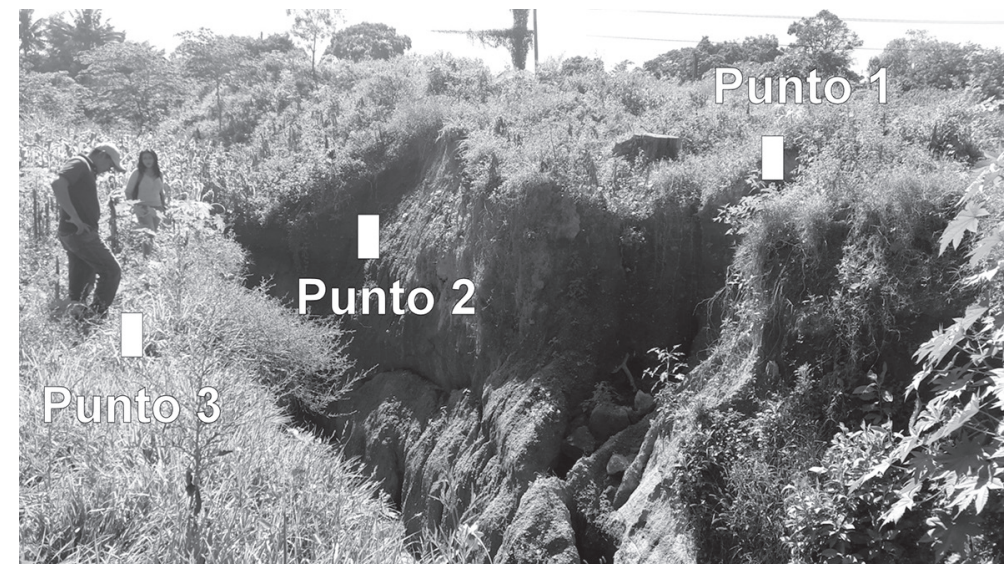

Fig. 6: Cárcava en carretera Panamericana (punto 1 de Fig. 5) al final del monitoreo. Puntos 1 y 2 tuvieron que ser replanteados.

\section{Comportamiento Erosión en cárcava Vía Galicia} (punto 2 de Fig. 5).

Debido a su comportamiento, este punto se relaciono a erosión subterránea (área tributara es pequeña). Presentando cambios a partir de la mitad de la época de lluvia (mes de septiembre) cuando las paredes de la cárcava compuestos por TBJ empezó a presentar saturación en su superficie y posterior desprendimiento de pequeñas porciones de suelo en la cara del talud en forma de flujos deslizantes (Fig. 12 y Cuadro 3).

Talud TBJ, ubicado en Autopista San Salvador - San Miguel (Carretera de Oro), al poniente del colegio Padre Arrupe, Soyapango. (punto 6 de Fig. 5)

Finalmente el punto 6, Talud frente a colegio Padre Arrupe, no presento mayores cambios verticales y horizontales durante el periodo del 2015, esto puede estar relacionado a que en el sector hay abundante vegetación arbustiva. Chavez et al. (2016) reporto desde 2013 en ese talud diferentes episodios de denudación por flujos deslizantes a lo largo del talud. Para las lluvias registradas, en el periodo del mes de octubre de 2015, se observaron pequeños flujos en algunos tramos de este talud (Fig. 13); así como también se produjeron derrumbes y flujos parciales en sectores adyacentes.

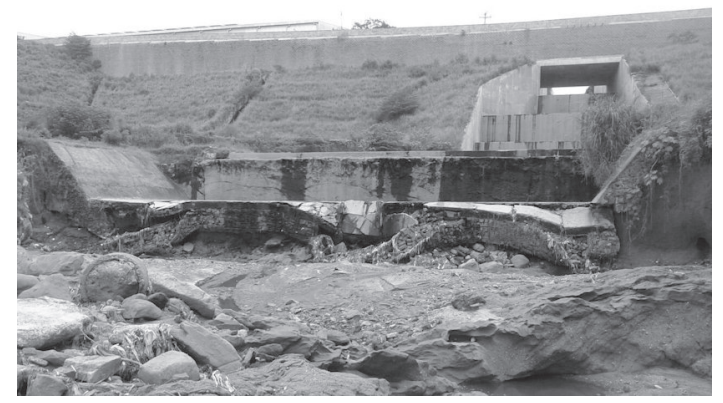

Fig. 7: Situación de la obra de paso en Noviembre 2015 (punto 5 de Fig. 5 y Fig. 3a) cuando ya estaba afectada nuevamente por erosión retrograda

\section{Cálculo de pérdida de suelo con método USLE (Universal Soil Loss Equation)}

Para la estimación de la erosión de la cuenca del río Las Cañas, se optó por el uso de la Ecuación Universal de la Perdida de Suelo, ecuación conocida como USLE (Universal Soil Loss Equation), por sus siglas en idioma inglés. USLE es un modelo diseñado para predecir la cantidad de pérdida de suelo por escurrimiento en áreas específicas bajo determinados sistemas de manejo y cultivos (Wischmeier y Smith, 1978). Para el caso del área de estudio contribuirá a tener un indicativo (tasa) en función de los usos de suelos actuales, con relación al tipo de suelo (TBJ) y las características de la lluvia de la zona. 


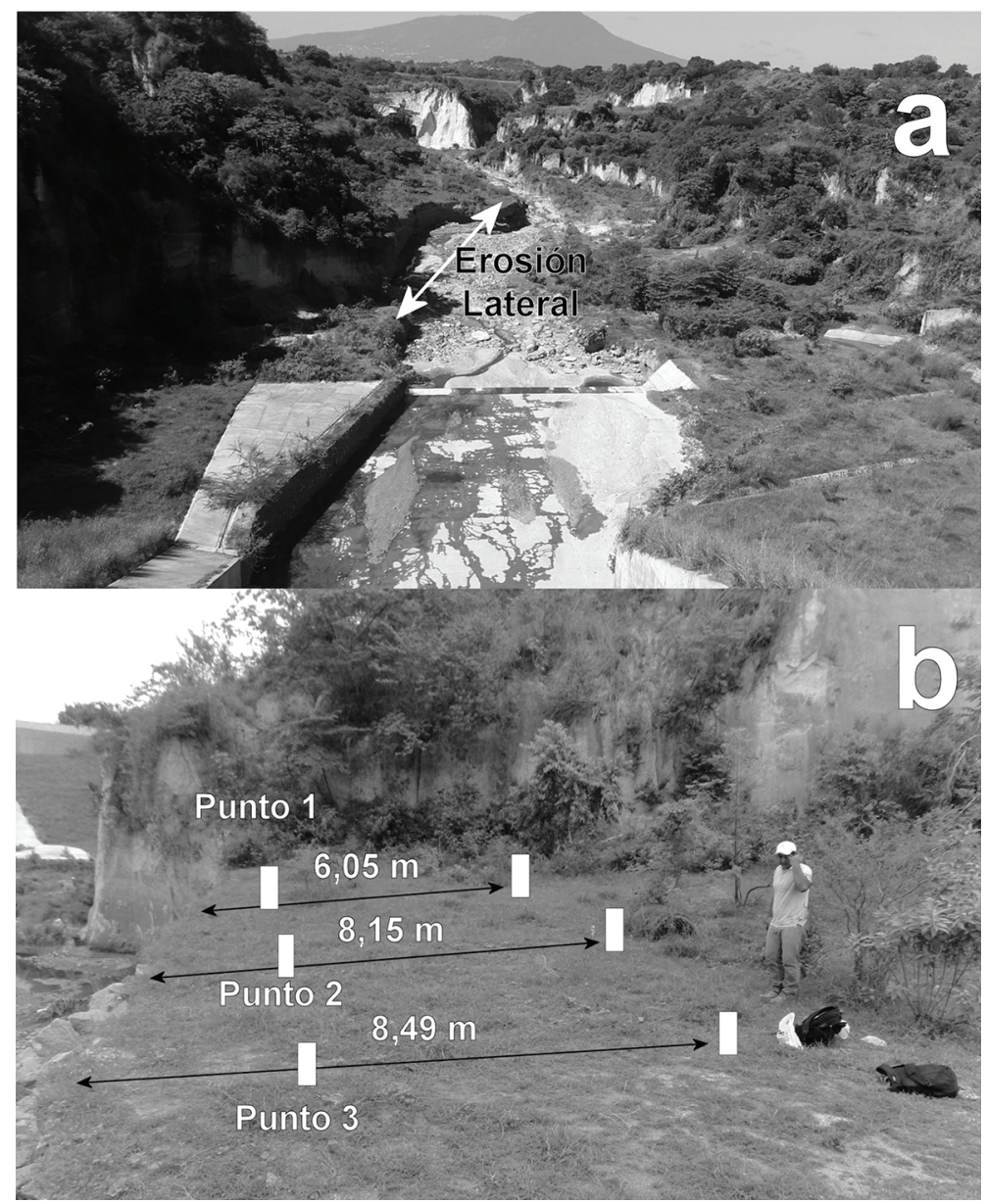

Fig. 8 Erosión lateral acaecida durante periodo de monitoreo (punto 5 de Fig. 5); además se muestra la distribución de pines en el punto 5 .

\section{Cuadro 3}

Datos finales del monitoreo de Cárcava Frente Residencial Vía Galicia (el signo positivo denota procesos de erosión y los negativos de azolvamiento).

\begin{tabular}{ccccccc}
\hline Fecha de Visita & \multicolumn{2}{c}{ Desplazamiento Vertical (mm) Acumulado } & \multicolumn{3}{c}{ Desplazamiento Horizontal (mm) Acumulado } \\
& Punto A & Punto F & Punto B & Punto A & Punto F & Punto B \\
\hline 26 de mayo 2015 & 0 & 0 & 0 & 0 & 0 & 0 \\
03 de Septiembre 2015 & 180 & 140 & -200 & 470 & 60 & 50 \\
23 Octubre de 2015 & 180 & 240 & 300 & 1270 & 290 & 50 \\
26 de noviembre de 2015 & 230 & -510 & 100 & 1270 & 860 & 50 \\
10 diciembre de 2015 & 230 & -510 & 100 & 1270 & 860 & 50 \\
\hline
\end{tabular}




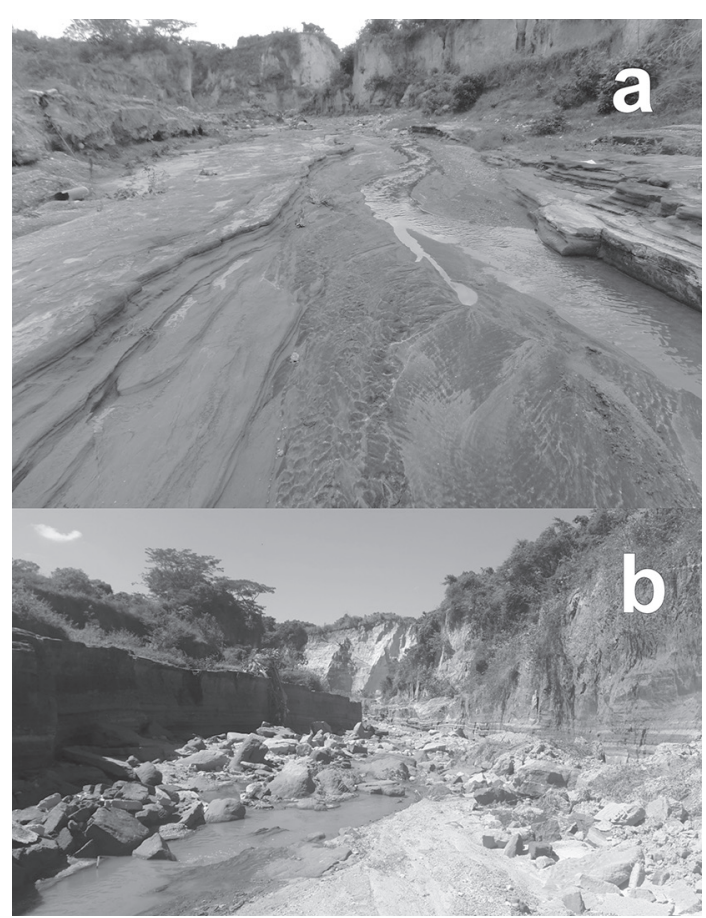

Fig. 9: Cambios en la profundización y ensanchamiento del cauce aguas abajo del punto de monitoreo 5 , entre mayo y diciembre de 2015 .

La expresión general del modelo USLE es la siguiente: $A=R$. K . L . S . C . P. Donde: A: pérdida de suelo (ton/ha*año); R: erosividad de la lluvia (Mj*mm/ha*hr*año); K: factor de erosividad del suelo (ton*hr/Mj*mm); L: factor por la longitud de pendiente (adimensional); S: factor de grado de pendiente (adimensional); C: factor de cubierta vegetal; $\mathrm{P}$ : factor por prácticas de manejo (adimensional).

El método estima el valor potencial o actual de erosión, teniendo en cuenta el uso actual del suelo y permite tener una visión acerca del riesgo de erosión ante el cambio del uso del suelo. Lo cual puede usarse para la demarcación de las zonas de protección de ríos y quebradas, así como, también para la definición de áreas de uso restringido.

Algunas consideraciones de la ecuación USLE (Vrieling, 2006) es que es un modelo empírico de promedios a largo plazo de erosión planar y de surcos de datos de parcelas del Este de Estados Unidos. Además que se necesita una serie de datos históricos con valores locales y a una buena escala para los parámetros $\mathrm{R}, \mathrm{K}$ y $\mathrm{C}$. Debido a esto USLE, puede servir como una referencia inicial, pero debe investigarse o crear modelos más cercanos a la realidad y que puedan ser calibrados, así como validados.

La estimación de la erosión hídrica requiere de información temática como suelos, clima, pendiente y cobertura y uso de la tierra, la cual, se puede automatizar a través de Sistemas de Información Geográfico (GIS) y mediante análisis espacial (superposición) pudiéndose obtener un mapa resultante que indica los rangos de erosión, en la figura 14 se plantea el flujograma de procedimiento que se siguió en GIS para el cálculo de la erosión hídrica potencial con el método USLE.

La información topográfica (años 80) y de cobertura vegetal (2012) usada corresponde a una escala 1:25000.

\section{Erosividad de la lluvia (R)}

El factor erosividad de la lluvia es un índice numérico que expresa la capacidad de la lluvia para erosionar el suelo, se define como la suma del producto de la energía cinética de la precipitación por su máxima intensidad en treinta minutos para todos los eventos importantes de precipitación en un área durante un año promedio (Wischmeier y Smith, 1978). Para su aplicación se requiere de un amplio registro de periodos de lluviosos, es por ello que para el presente estudio se optó por la utilización de un buen número de ecuaciones empíricas (Cuadro 4) para el cálculo de la energía cinética de una lluvia, las cuales se expresan en función de la intensidad de lluvia (IDF), con la condicionante que se debe disponer de datos de intensidades con frecuencias de 30 minutos o superior.

Para este caso en particular se dispuso de la información de las curvas IDF de las Estaciones de Ilopango (S10), Boquerón (L18), Observatorio 

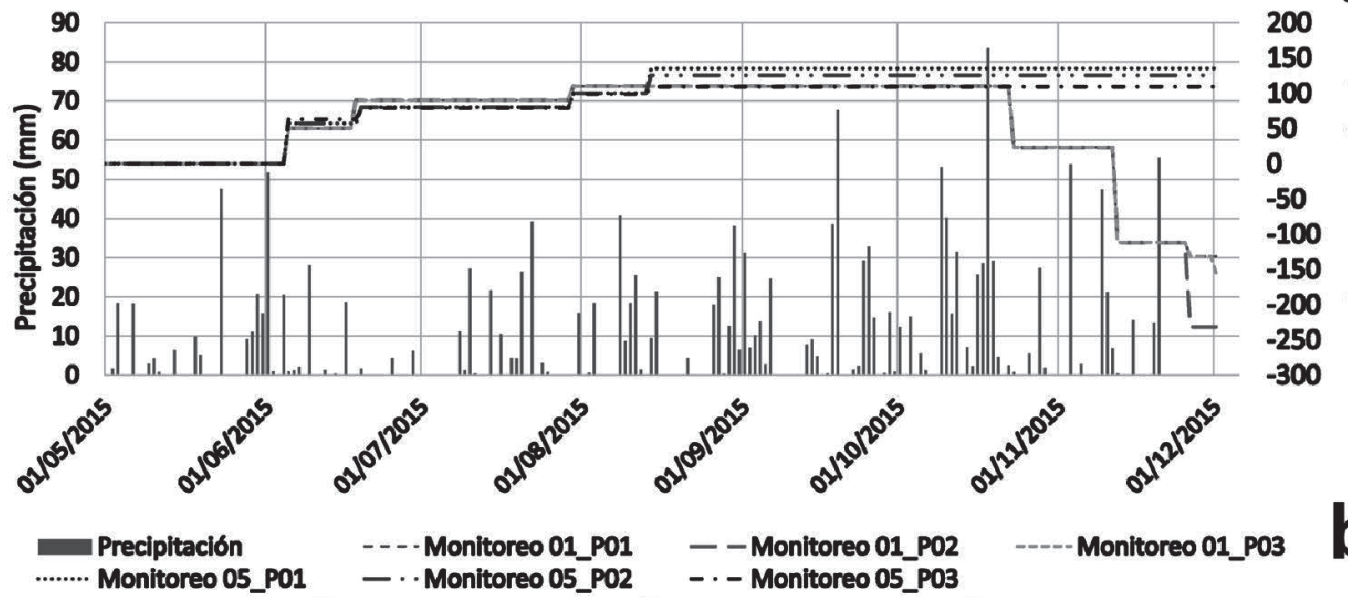

Monitoreo 01_P03
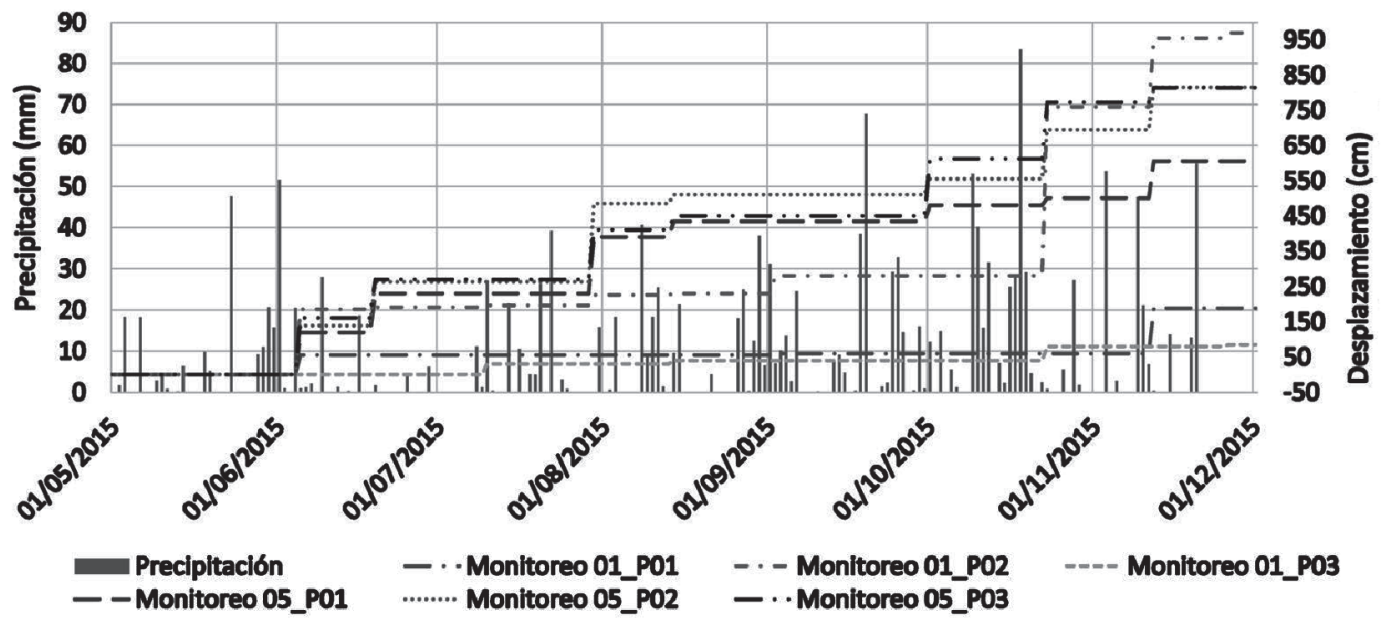

----- Monitoreo 01_P03

Fig.10 De puntos 1 y 5 de Fig. 5. Se muestran desplazamientos horizontales (a), verticales (b) en cm y precipitaciones durante periodo de monitoreo $(\mathrm{mm})$. El signo positivo denota procesos de erosión y los negativos de azolvamiento.

Cuadro 4

Relaciones empíricas entre la energía cinética, EC (MJ *ha-1 *mm-1) e intensidad de la lluvia, I (mm h-1) en distintos lugares, con indicación del rango de intensidad de los datos utilizados (n.c.: no consta) (Angulo, 2012).

\begin{tabular}{ccc}
\hline Fuente, Localidad & Ecuación & $\begin{array}{c}\text { Rango de intensidad } \\
(\mathrm{mm} / \mathrm{h})\end{array}$ \\
\hline USLE; Wischmeier y Smith 1978; basado en Laws and Parsons (1943) & $\mathrm{EC}=0,0119+0,0873 \log 10$ (I) & $0,4-144$ \\
Marshall and Palmer (1948). País: EE.UU Cerro et al., (1998) Barcelona & $\mathrm{EC}=0,384[1-(0,54 \mathrm{e}-0,029(\mathrm{I}))]$ & $1-150$ \\
Jayawardena y Rezaur (2000) Hong Kong & $\mathrm{EC}=0,369[1-(0,69 \mathrm{e}-0,038(\mathrm{I})]$ & $12-120$ \\
Van Dijk et al., (2002) Universal & $\mathrm{EC}=0,283[1-(0,52 \mathrm{e}-0.042(\mathrm{I})]$ & n.c. \\
Hudson (1965) Zimbawe & $\mathrm{EC}=0,298(1-4,29 / \mathrm{I})$ & n.c. \\
RUSLE; Brown and Foster (1987) Sur EE.UU & $\mathrm{EC}=0,29[1-(0,72 \mathrm{e}-(\mathrm{I} / 20))]$ & $0-250$ \\
\hline
\end{tabular}




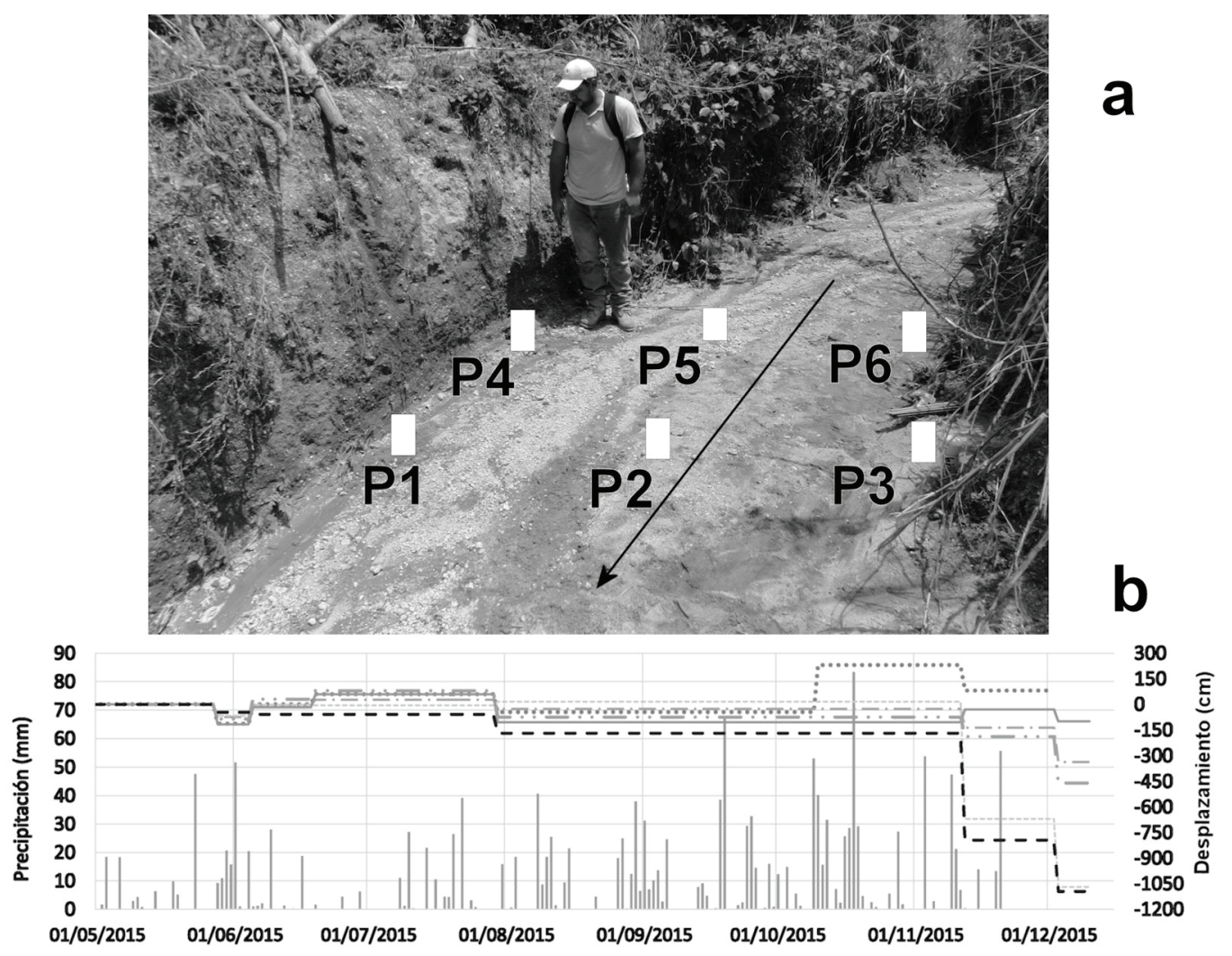

Precipitación …. Monitoreo P01 - - Monitoreo P02 Monitoreo P03 — Monitoreo P04 — - Monitoreo P05 - - Monitoreo P06

Fig. 11: Ubicación de puntos de monitoreo y comportamiento de erosión ( $\mathrm{mm}$ ) en lecho de cauce de punto 3 de Fig. 5, se denotan el comportamiento erosivo y azolvamiento de los pines colocados en campo. El signo positivo denota procesos de erosión y los negativos de azolvamiento.

(S5), Santa Tecla (L8), ITIC (S4), Aguilares (C8) y San Diego (L-36) (Fig. 1), a las cuales se utilizaron las diferentes ecuaciones mostradas en la cuadro 4, para diferentes periodos de retorno y con un tiempo de lluvia de 30 minutos. El objetivo de utilizar diferentes ecuaciones para el cálculo de la energía cinética de la lluvia, es para obtener un umbral de datos más amplio, desarrollar comparaciones y obtener un valor promedio del factor R.

En el cuadro 5 se presenta el resumen de cálculo de Índice de erosividad de lluvia, el cual sirvió para la construcción del mapa raster del factor $\mathrm{R}$, en donde se utiliza la interpolación, por medio de ArcGIS y la secuencia: Arc toolbox- Spatial Analyst -ToolsInterpolation-Kringing; seleccionando los datos de periodo de retorno de las diferentes estaciones.

\section{Factor de erosividad del suelo (K)}

El factor de erosividad el suelo (K), es una descripción cuantitativa de la erodibilidad inherente de un suelo determinado, expresada en unidades de pérdida de suelo ( $\mathrm{t} / \mathrm{ha}$ ) por cada punto de $\mathrm{R}(\mathrm{Mj} * \mathrm{~mm} / \mathrm{ha} * \mathrm{~h})$. Este factor refleja el hecho de que diferentes suelos se erosionan a diferentes tasas cuando los demás factores que afectan la erosión son los mismos (Kirkby et al., 1984). Este factor K es función de cinco parámetros del suelo: porcentaje de limo más arena fina, porcentaje de arena, contenido de materia orgánica, estructura y permeabilidad.

Para el cálculo del factor K se debe de contar con información geotécnica del área de estudio 


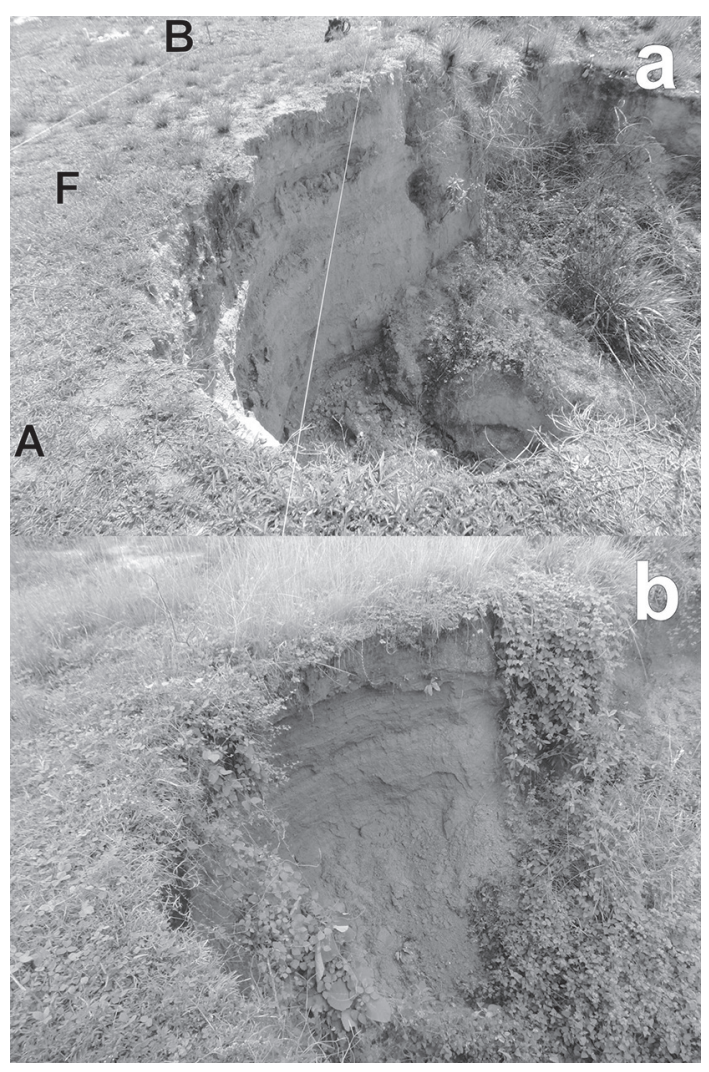

Fig. 12: Erosión en cárcava Vía Galicia (punto 2 de Fig. 5), relacionada a erosión subterránea.

Cuadro 5

Resumen de cálculo de Índice de erosividad de lluvia. Para diferentes estaciones del AMSS.

\begin{tabular}{cccc}
\hline \multirow{2}{*}{ Estación } & \multicolumn{3}{c}{$\begin{array}{c}\text { Índice de Erosión Pluvial R } \\
{\left[\left(\mathrm{MJ} * \mathrm{~mm} /\left(\mathrm{ha} \mathrm{R}^{\mathrm{h}}\right)\right]\right.}\end{array}$} \\
\cline { 2 - 4 } & 5 años & 10 años & 25 años \\
\hline Ilopango & 2606,7246 & 3151,24637 & 3872,1946 \\
Boquerón & 2272,1326 & 2711,53703 & 3305,0902 \\
Observatorio & 2606,7246 & 3151,24637 & 3956,8494 \\
Tecla & 2746,9292 & 3462,57157 & 4529,3069 \\
ITIC & 2606,7246 & 3151,24637 & 3956,8494 \\
Aguilares & 2239,9249 & 2676,37217 & 3266,2882 \\
San Diego & 3189,3663 & 4085,5388 & 5336,0479 \\
\hline
\end{tabular}

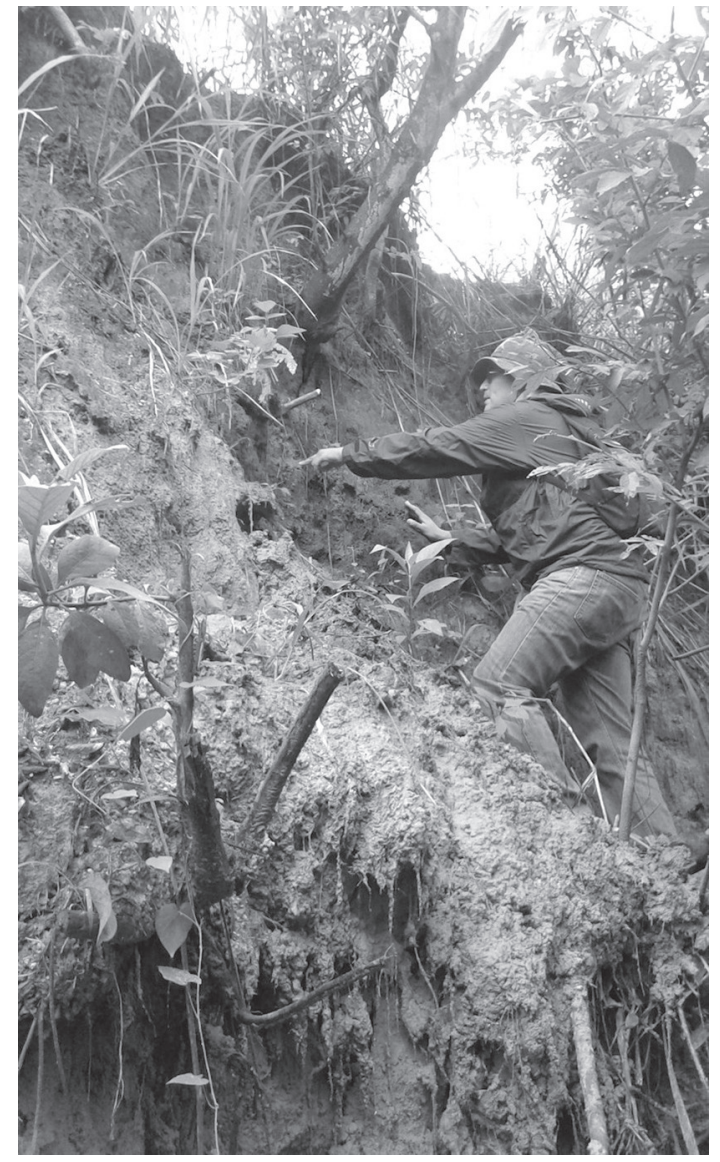

Fig. 13: Talud TBJ, ubicado en Autopista San Salvador - San Miguel (Carretera de Oro), al Poniente del colegio Padre Arrupe, Soyapango. (punto 6 de Fig. 5).

para ello se utilizó con información geotécnica (68 pruebas) de Molina et al. (2009) y que corresponde a la cuenca del río Las Cañas, obteniéndose los parámetros necesarios para poder leer los valores del nomograma presentado en Kirkby et al. (1984). Una de las limitantes en la aplicación de ciertos datos geotécnicos, es que se generaliza en toda el área de estudio estos parámetros, sin embargo representa una buena aproximación en esta metodología, siendo los rangos de variabilidad de estos parámetros muy estrecha respecto a otros estudios geotécnicos en suelos del tipo TBJ en la misma área. 


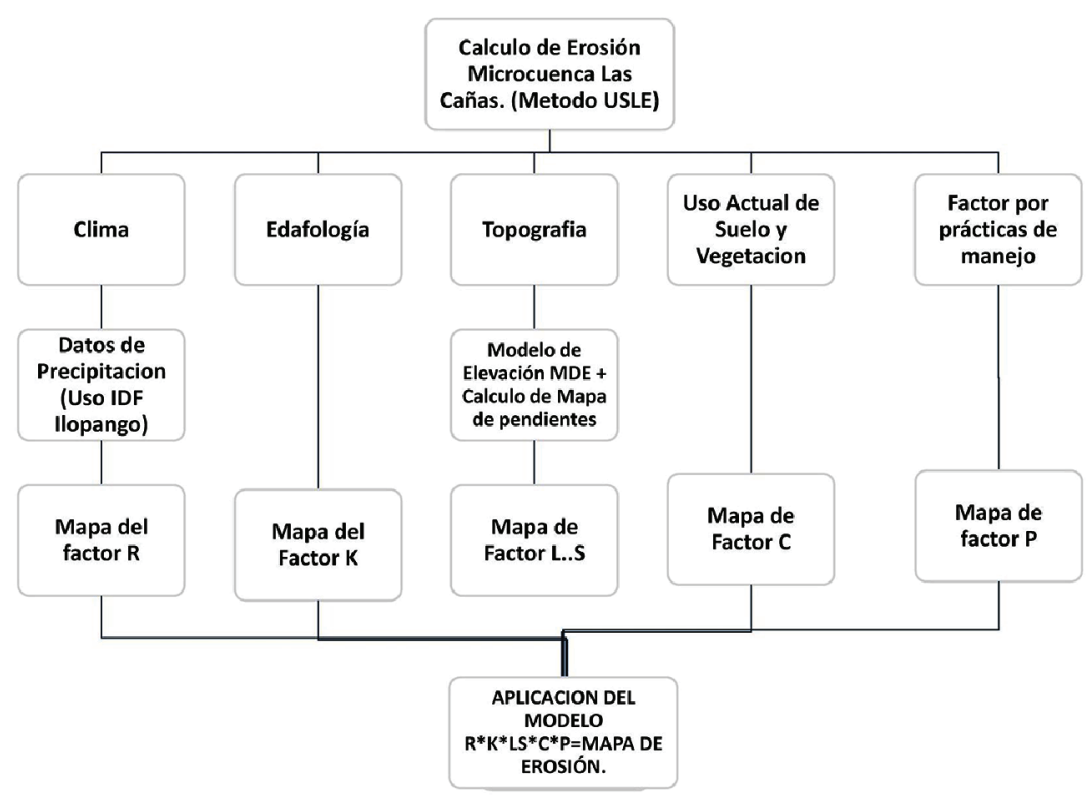

Fig. 14: Flujograma de procedimientos a seguir para calcular la pérdida de suelo USLE.

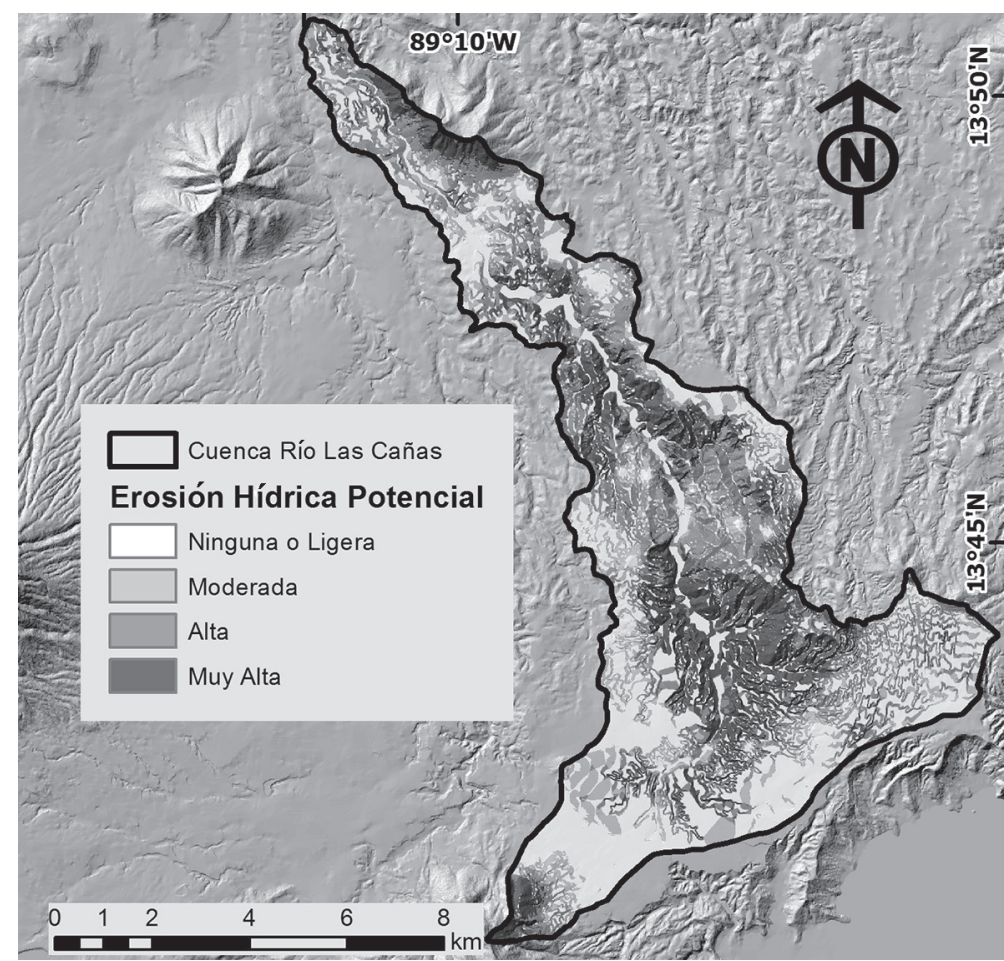

Fig. 15: Mapa de pérdida de suelo anual estimado USLE de cuenca las Cañas. 


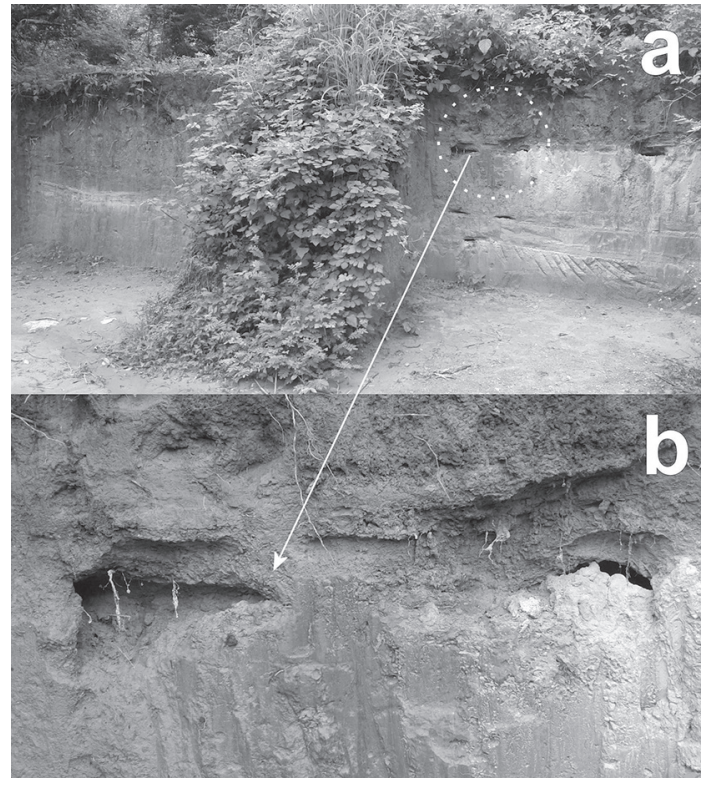

Fig. 16: Campo experimental de taludes de TBJ con diferente inclinación y cobertura donde se monitorea la humedad y succión. Se puede observar posible influencia de la erosión subterránea en los proceso de denudación en estos piroclastos.

Posterior al cruce de información de nomograma K de Kirkby et al. (1984) versus los parámetros geotécnicos de suelos de Molina et al. (2009), se determinó que los valores de $\mathrm{K}$ para suelos del tipo TBJ ensayados, oscilan entre 0,005 a 0,007 . Para rasterizar esta información, se optó por asociar valores de $\mathrm{K}$ a los diversos usos de suelos del mapa de usos de suelo (MARN, 2013), de esta forma se obtuvo un mapa de factor de $\mathrm{K}$ con una adecuada distribución en el área y los más aproximado a la realidad; es de destacar que para áreas urbanísticas se utilizó un valor nulo de índice de erodibilidad (esto porque en estas áreas no se espera registrar erosión hídrica por causa de la impermeabilización), la asignación y distribución de muestra en el cuadro 6.

Factor de longitud de pendiente, L, y el factor de gradiente de pendiente $S$

Los efectos de la longitud y el gradiente de la pendiente se representan en método USLE como L y S, respectivamente; sin embargo, a menudo se evalúan como un factor topográfico único, LS. La longitud de la pendiente se define como la distancia desde el punto de origen del flujo sobre la superficie hasta el punto donde la pendiente disminuye lo bastante como para que ocurra la depositación o hasta el punto en que la escorrentía entra en un canal definido. El canal puede ser parte de una red de drenaje a un canal construido. El gradiente de la pendiente es el campo o segmento de pendiente, expresado generalmente como un porcentaje. El desarrollo de la USLE se basó en la longitud de una parcela estándar de 22,13 metros por lo tanto, el factor de longitud de pendiente se definió como (Kirkby et al., 1984):

$$
\mathrm{L}=(\mathrm{x} / 22,13)^{\mathrm{m}}
$$

En donde: L: factor de longitud de la pendiente; $\mathrm{x}$ : longitud de la pendiente, en metros y $\mathrm{m}$ un exponente.

$$
\begin{aligned}
& \mathrm{m}=\mathrm{F} /((1+\mathrm{F})) \\
& \mathrm{F}=(\operatorname{SIN} \beta / 0,0896) /\left(3(\operatorname{SIN} \beta)^{0,8}+0,56\right)
\end{aligned}
$$

$\beta$ : ángulo de la pendiente

El factor de inclinación (S) de la pendiente refleja la influencia del gradiente de la pendiente en la erosión. El potencial de erosión se incrementa con la inclinación de la pendiente. Para el cálculo del factor S, se tomó en cuenta la siguiente ecuación:

$$
\begin{aligned}
& \mathrm{S}=10,8 * \operatorname{SEN} \beta+0,03 \text { CUANDO } \mathrm{S}<9 \% \\
& \mathrm{~S}=16,8 * \operatorname{SEN} \beta-0,5 \quad \text { CUANDO } \mathrm{S} \geq 9 \%
\end{aligned}
$$

Donde

$\mathrm{S}$ : factor de inclinación de pendiente;

$\mathrm{S}$ : inclinación de pendiente [\%] y

$\beta$ : ángulo de pendiente $\left[{ }^{\circ}\right]$

Para el cálculo del factor LS, se utilizó como capa base el modelo de elevación digital con tamaño de pixel de 10×10 m, del cual se generaron modelos grid, de mapa de pendientes en grados (slope grados) por medio de la herramienta de Arctoolbox-Spatial Analisys Tool-Surface-slopes 
Cuadro 6

Valores de Erodibilidad de suelos K para la cuenca río Las Cañas.

\begin{tabular}{lccc}
\hline Categoría & $\begin{array}{c}\text { Área } \\
(\mathrm{km})\end{array}$ & $\begin{array}{c}\text { K Unidades Ingle- } \\
\text { sas (ton*acre*hr)/ } \\
(\text { acre*ft*ton*plg) }\end{array}$ & $\begin{array}{c}\text { K Unidades Metricas } \\
\text { (ton*ha*hr)/(ha*Mj.mm) }\end{array}$ \\
\hline Tejido Urbano Continuo & 19,08 & 0,001 & 0,00013 \\
Cultivos, Pastos y Granos Básicos & 18,75 & 0,42 & 0,05531 \\
Vegetación Arbórea & 16,85 & 0,43 & 0,05663 \\
Vegetación Herbácea & 6,21 & 0,43 & 0,05663 \\
Tejido Urbano Discontinuo & 4,35 & 0,001 & 0,00013 \\
Zonas Industriales y Logísticas & 3,13 & 0,001 & 0,00013 \\
Café & 3,03 & 0,45 & 0,05927 \\
Zona de Denudación & 1,26 & 0,9 & 0,11853 \\
Bosque de Galería & 0,58 & 0,45 & 0,05927 \\
Zonas de Extracción de Arena & 0,29 & 0,8 & 0,10536 \\
Árboles Frutales & 0,15 & 0,42 & 0,05531 \\
Zonas Comerciales (grandes Cen- & 0,11 & 0,001 & 0.00013 \\
tros Comerciales) & & 0,001 & 0,00013 \\
Parque Recreativo & 0,06 & 0,53 & 0,0698 \\
Caña de Azúcar & 0,01 & & \\
\hline
\end{tabular}

y utilizando también Arctoolbox-Spatial Analisys Tool-Hydrology- FILL- Flow Directions - Flow Acumulation que generan grid de dirección de flujo (Flow direction) y un grid de acumulación de flujo (Flow Acumulation), necesarios para el cálculo de F, m, L y S; cálculos que fueron realizados por medio de la herramienta de GIS Raster calculator dando como resultado el mapa de longitud y el gradiente de la pendiente.

Factor de manejo de cultivo $C$, y Factor de prácticas de control de erosión $P$

El factor de manejo de cultivo $\mathrm{C}$ representa la relación de pérdida del suelo a partir de una condición específica de cultivo o cobertura con la pérdida del suelo (Kirkby et al., 1984). Este factor incluye los efectos interrelacionados de la cubierta, la secuencia de cultivos, el nivel de productividad, duración de la estación de crecimiento, prácticas de cultivo, manejo de residuos y distribución de la precipitación pluvial. La evaluación del factor $\mathrm{C}$ es a menudo difícil debido a los múltiples sistemas de cultivo y manejo del suelo.

El factor del método de control de la erosión $\mathrm{P}$ es la proporción de la pérdida de suelo cuando se hace uso de alguna practica especifica en comparación a la pérdida de suelo, cuando se cultiva en laderas de las colinas los métodos de control de la erosión que por lo general se incluyen en este factor son la delineación de contornos, el cultivo en franjas de contorno y el terraceo (Kirkby et al., 1984). Para el caso de la cuenca río Las Cañas por no contarse con prácticas formales de control de la erosión las ponderaciones asignadas oscilan entre 0,80 a 1 .

En el cuadro 7 se presentan los diferentes valores de $\mathrm{C}$ y $\mathrm{P}$ asignados a los diferentes usos de suelos del área de estudio, cabe aclarar que estos fueron establecidos conforme a las condiciones de manejo de cultivo y las prácticas de control de erosión que se han observado en campo. 


\section{Cuadro 7}

Asignación de Factor de manejo de cultivo C, y Factor de prácticas de control de erosión, para usos de suelos de cuenca río Las Cañas.

\begin{tabular}{lccc}
\hline Categoría & Área $(\mathrm{km})$ & Factor C & Factor P \\
\hline Tejido Urbano Continuo & 19,08 & 0 & 1 \\
Cultivos, Pastos y Granos Básicos & 18,75 & 0,8 & 1 \\
Vegetación Arbórea & 16,85 & 0,1 & 0,8 \\
Vegetación Herbácea & 6,21 & 0,1 & 0,8 \\
Tejido Urbano Discontinuo & 4,35 & 0 & 1 \\
Zonas Industriales y Logísticas & 3,13 & 0 & 1 \\
Café & 3,03 & 0,3 & 0,8 \\
Zona de Denudación & 1,26 & 1 & 1 \\
Bosque de Galería & 0,58 & 0,1 & 0,8 \\
Zonas de Extracción de Arena & 0,29 & 1 & 1 \\
Árboles Frutales & 0,15 & 0,1 & 1 \\
Zonas Comerciales (grandes Centros Comerciales) & 0,11 & 0 & 1 \\
Parque Recreativo & 0,06 & 0,8 & 1 \\
Caña de Azúcar & 0,01 & 0,7 & 0,9 \\
\hline
\end{tabular}

\section{Mapa de pérdida de suelo anual estimada}

Para poder clasificar el tipo de erosión resultante de la aplicación del método USLE para la cuenca del río Las Cañas, se definen rangos de pérdidas de suelo, siendo la clasificación más extendida la denominada como Clasificación Provisional para la Evaluación de la Degradación de los Suelos (Cuadro 8 y Figura 15) (Giménez, 2008). Este mapa se obtuvo haciendo uso de mapas de factores y de operaciones de raster al aplicar la ecuación $A=R$. K . L . S . C . P. en ArcGIS.

\section{DISCUSIÓN Y CONCLUSIONES DE RESULTADOS}

Durante el crecimiento urbano en el AMSS no siempre se tomo en cuenta el área perteneciente a los sistemas de drenaje primarios (es decir se invadieron, rellenaron, modificaron, alterando su caudal y área de influencia de las cuencas (Chavez et al., 2014a). Estas acciones antrópicas han afectado el nivel base y el equilibrio de los drenajes resultando que hoy en día se tienen
Cuadro 8

Clasificación para la evaluación de la degradación de los suelos creada por FAO, PNUMA y UNESCO (Giménez. 2008).

\begin{tabular}{cc}
\hline $\begin{array}{c}\text { Pérdidas de Suelo A } \\
(\text { Ton/ha*año })\end{array}$ & Grado de la Erosión Hídrica \\
\hline$<10$ & Ninguna o Ligera \\
$10-50$ & Moderada \\
$50-200$ & Alta \\
$>200$ & Muy Alta \\
\hline
\end{tabular}

muchos problemas de inundación y erosión en varios sectores. Estos cambios importantes en los drenajes, que se dan en periodos muy cortos (incluso cada año) hace urgente la investigación de las causas y en base a eso qué medidas se pueden tomar; siendo importante tratar de comprender los procesos naturales, para la toma de mejores decisiones cuando se proyecten intervenciones antrópicas o medidas de mitigación estructurales o no.

Durante el monitoreo realizado se observó que los mayores cambios se dieron durante la época lluviosa, dándose los cambios más fuertes durante los periodos continúo de lluvia (temporal) y 
posteriores lluvias con intensidades fuertes (esto por condiciones de saturación de suelo). Las zonas donde se cuenta con una exposición directa a escorrentía superficial, son los más afectados por los procesos erosivos, la acumulación de material o azolvamiento observados son producto del colapso del material.

La metodología de reconocimiento (Hudson, 1997) que consiste en la colocación de varillas de $3 / 8$ de pulgadas con una longitud no mayor a 40 centímetros, utilizada durante la presente investigación dio resultados satisfactorios requiriendo bajos recursos para llevarla a cabo, sin embargo, es necesario tener puntos de referencia en sectores cercanos para hacer el replanteo de nuevos sitios si los puntos colocados se pierden por la erosión o por intervenciones antrópicas o de animales. El uso de drones o UAV (Vehículos Aéreos no Tripulados) facilitaría la obtención de resultados ya que pueden usarse para obtener modelos de elevación y comparar los cambios en el tiempo (Casella et al., 2016).

Al comparar resultados de USLE de esta investigación contra el mapa de Kim et al. (2005) se comprueba que a pesar de la diferencia de escala entre ambas investigaciones, la cuenca de las Cañas siempre se demarca como de Alta a Muy Alta erosión.

Kim et al. (2005) realizaron estudio de la cuenca del Lempa donde se encuentra inmerso el río las Cañas y concluyen que el promedio para toda la cuenca del Lempa es de 120 ton ha $^{-1}$ año ${ }^{-1}$. El promedio para las Cañas (USLE), obtenido durante la presente investigación, fue de 168,9 ton $\mathrm{ha}^{-1} \mathrm{año}^{-1}$. Un valor típico para laderas inclinadas de Centroamérica es de 300 ton $\mathrm{ha}^{-1}$ año $^{-1}$. Durante la etapa de campo se obtuvieron valores bastantes elevados (Cuadro 1).

Con resultados del mapa USLE generado, los rangos de erosión predominantes son NingunaLigera (33,76\%); Alta (25,73\%); Muy Alta $(23,46 \%)$ y Moderada (17,05\%). La categoría de Muy Alta y Alta erosión suceden principalmente en las zonas de Badlands, Laderas de Erosión y Relieve Policíclico Sobre Restos de Ilopango Antiguo o Bálsamo (Fig. 2); lo cual coincide con lo observado en campo (Chavez et al., 2016). En cuanto a los usos de suelo, la zona de Muy Alta susceptibilidad a erosión está compuesta principalmente por zonas de cultivos, pastos y granos básicos, vegetación arbórea y herbácea. La zona de Alta susceptibilidad a erosión está compuesta por cultivos, pastos y granos básicos, tejido urbano continuo, vegetación arbórea y herbácea. El promover practicas adecuadas en zonas de cultivos y proteger los bosques o vegetación natural podría ayudar a controlar la erosión. Pero también es importante investigar sobre la influencia de la tectónica, cambios en el nivel base y actividades antrópicas que podrían estar intensificando los procesos de denudación.

En el cuadro 9 se compara los valores obtenidos durante el monitoreo y los del mapa USLE. Los resultados están indicando que al no contar con manejo adecuado del suelo, ausencia de prácticas de control de erosión y cambios de uso de suelo, muchas zonas han incrementado desde erosión moderada o ligera a tener muy alta susceptibilidad a la erosión. Es de tomar en cuenta que método USLE se desarrolló en base al clima, suelos, topografía y escenarios que posiblemente no corresponden a una zona tropical, por lo que resultados obtenidos podrían estar subestimados (Kim et al., 2005). Las diferencias entre lo medido en campo y el mapa USLE pueden estar influenciados por los procesos urbanísticos y controles externos (actividades antrópicas, clima, nivel base y tectónica). También dentro de los procesos de denudación (que incluye a la erosión) hay que incorporar las propiedades de la TBJ, así como los movimientos de ladera que se relacionan y combinan con la erosión acelerando la dinámica del sector. Estos procesos podrían afectar en mayor o menor grado dependiendo de ocurrencia de lluvias intensas o terremotos (Chavez et al., 2016). La actualización y mejora de escala del modelo de elevación, mapa de edafología, prácticas de manejo, así como los usos de suelo ayudarían a recalcular los parámetros y resultados del mapa USLE obtenido.

Durante visitas a los sectores con TBJ en el AMSS y el monitoreo realizado durante la presente investigación se ha evidenciado, que la erosión subterránea podría ser un factor importante, y por tanto se requiere estudiar más la influencia de la succión (Chavez et al., 2016), los procesos 
Cuadro 9

Comparación de los valores obtenidos durante el monitoreo y los del mapa USLE.

\begin{tabular}{ccc}
\hline Descripción & Mapa USLE & Campo \\
\hline 1. Cárcava Carretera Panamericana & Fuera de zona de estudio & Fuera de zona de estudio \\
2. Cárcava Vía Galicia I & Alta & Muy Alta \\
3. Lecho de Cauce & Moderada & Muy Alta \\
4. Obra de Descarga Texaco & Moderada & Muy Alta \\
5. Talud Zona Franca & Alta & Muy Alta \\
6. Talud Padre Arrupe & Fuera de zona de estudio & Fuera de zona de estudio \\
7. Talud Via Galicia & Ligera & Muy Alta \\
8. Talud Arrupe I & Fuera de zona de estudio & Fuera de zona de estudio \\
9. Talud Arrupe II & Fuera de zona de estudio & Fuera de zona de estudio \\
10. Talud Cipreses I & Ligera & Muy Alta \\
11. Talud Cipreses II & Ligera & Muy Alta \\
12. Talud Zona Franca I & Muy Alta & Muy Alta \\
13. Sección Cauce Zona Franca II (lado derecho) & Moderada & Muy Alta \\
13. Sección Cauce Zona Franca II(lado izquierdo) & Alta & Muy Alta \\
14. Talud UES & Fuera de zona de estudio & Fuera de zona de estudio
\end{tabular}

de infiltración, permeabilidad, meteorización, influencia de vegetación y sus raíces, así como movimiento de las aguas subterráneas. Llama la atención que los puntos de denudación monitoreados por Chavez et al. (2016) y por los autores no cuentan con un área tributaria importante de recolección de escorrentía superficial. En estos casos se requiere mayor investigación para determinar comportamiento de infiltración y movimiento de agua sub-superficial. Actualmente los autores están realizando monitoreo de humedad y succión en un campo experimental de la UES con taludes de TBJ con diferente inclinación y cobertura. Los resultados preliminares (Fig. 16) indican también la posible influencia de la erosión subterránea en los proceso de denudación en estos piroclastos.

Los drenajes que conforman la cuenca del río las Cañas (zona de estudio) muestran en diferentes tramos canales aluviales (Charlton, 2008) tipo rectos, anastomosados y meándricos (bastantes quedan abandonados con el tiempo) lo cual indica la influencia de la pendiente en su morfología, así como su ajuste en el tiempo y la cantidad de sedimentos que transporta el río.
La cuenca del río las Cañas ha mostrado en las últimas décadas, procesos erosivos intensos tales como ensanchamiento y profundización del cauce; lo que se evidencia aun mas en las visitas de campo y en el análisis de imágenes satelitales. Se puede interpretar que las obras hidráulicas como puentes, canalizaciones o bóvedas, repercuten en cambios drásticos en el perfil de equilibrio del río y quebradas, ya que subdividen el drenaje natural en diferentes porciones modificándose el nivel base; así mismo el drenaje luego de una intervención puntual busca alcanzar su perfil de equilibrio, manifestándose en ciclos constantes de erosión o sedimentación (Chávez et al., 2014a). Muchos de los drenajes han pasado de transportar caudal solamente durante el periodo de invierno a transportar caudal en sus canales todos los días del año, debido a descargas de agua lluvia, grises y negras de las ciudades, teniendo su caudal máximo durante el invierno.

En cuanto a la extracción de áridos en el río las Cañas, Escobar et al. (1986) estimo una tasa de extracción de $1125 \mathrm{~m}^{3} /$ día, obteniendo 448 875 toneladas anuales. En el año 2011 se estimó 
una extracción diaria de 1300 toneladas lo que equivale a 474500 toneladas anuales (El Diario de Hoy, 2011), siendo este una de las acciones antrópicas que contribuye a que no se generen las condiciones de equilibrio del río, afectando de manera directa a sus afluentes y aumentando la problemática de erosión de la zona.

La influencia de la tectónica en el fenómeno erosivo de la cuenca no se ha cuantificado, pero Baxter (1995) y autores de esta investigación (Chavez et al., 2014), reportan fallamiento a lo largo de las secciones de los cauces; incluso después del terremoto de 1986, habitantes de la zona narran que el río las Cañas cambio su curso (J. Chavez, com. pers., 2006). Actualmente los autores están liderando investigación del movimiento de la superficie del AMSS haciendo uso de interferometría, con imágenes de radar del periodo de 2006 al 2011 de ALOS (Advanced Land Observing Satellite), así como Sentinel 1 (C band synthetic aperture radar) de 2015-2016 y los resultados preliminares indican movimientos de la superficie en cuenca alta del río las Cañas que podría estar relacionado a tectónica o a disminución del nivel de acuífero por extracción de agua en pozos, esto podría provocar problemática de erosión intensa en el sector.

En la cuenca alta del río las Cañas constantemente se dan procesos de denudación y reparación de la infraestructura desde hace décadas (Baxter, 1995) (Fig. 3 y 4). Recientemente en la zona de estudio se completó un proyecto llamado Climate Change Adaptation in Urban Areas in Central America, El Salvador (2016) liderado por el Gobierno Central, donde se realizo una modelación de deslizamientos pero al no tomarse datos geotécnicos reales de la TBJ y la geomorfología fluvial, los resultados no fueron completamente satisfactorios y las propuestas de mitigación para el sector podrían no estar acorde con lo observado en campo en taludes de TBJ por Chavez et al. (2016).

Todos estos aspectos deben investigarse con mayor detalle para tratar de predecir la dinámica erosiva y zonas que podrían verse más afectadas en el futuro, además de planificar los usos de suelo y obras estructurales/no estructurales necesarias.

\section{AGRADECIMIENTOS}

Deseamos reconocer apoyo recibido de parte de Consejo de Alcaldes y de la Oficina de Planificación del Área Metropolitana de San Salvador (COAMSS/OPAMSS), Escuela de Ingeniería Civil y facultad de Ciencias Agronómicas de la Universidad de El Salvador. Agradecemos a las personas que revisaron este artículo y editores, cuyos comentarios mejoraron su calidad.

\section{REFERENCIAS BIBLIOGRÁFICAS}

Angulo, M. (2012). El factor climático en la erosión del suelo: erosividad de la lluvia en la cuenca del Ebro (Tesis de doctorado). Universidad de Zaragoza, Zaragoza, España.

Aucelli, P., Conforti, M., Seta, M., del Monte, M., D’uva, L., Rosskopf, C. y Vergari, F. (2016). Multi-temporal digital photogrammetric analysis for quantitative assessment of soil erosion rates in the landola catchment of the upper Orcia valley (Tuscany, Italy). Land Degradation \& Development, 27(4), 1075-1092.

Baxter, S. (1995). Impacto ambiental en el río las Cañas. San Salvador: Ed. Biblioteca BANCASA.

Casella, E., Rovere, A., Pedroncini, A., Stark, C., Casella, M., Ferrari, M. y Firpo, M. (2016). Drones as tools for monitoring beach topography changes in the Ligurian Sea (NW Mediterranean). Geo-Marine Letters, 36 (2): 151-163.

Chávez, J., Hernandez, W. y Kopecky, L. (2012). Problemática y conocimiento actual de las tefras Tierra Blanca Joven en el Área Metropolitana de San Salvador, El Salvador. Revista Geológica de América Central, 47, 117-132. 
Chavez, J., Lopez, R., Kopecky, L. y Landaverde, J. (2013). Soil-Water retention curve and beginning of monitoring in Tierra Blanca Joven (TBJ). Revista Geológica de América Central, 49, 83-99.

Chavez, J., Šebesta, J., Kopecky, L., Lopez, R. y Landaverde, J. (2014a). Application of geomorphologic knowledge for erosion hazard mapping. Natural Hazards, 71, 1323-1354.

Chavez, J., Landaverde, J., Ayala, O. y Mendoza, L. (2014b). Application of constitutive models in the volcanic tephra "Tierra Blanca Joven”. Ingeniería, 24(2), 53-78.

Chávez, J., Landaverde, J., Mendoza, L., Lopez, R. y Tejnecký, V. (2016). Monitoring and behavior of unsaturated volcanic pyroclastic in the Metropolitan Area of San Salvador, El Salvador. SpringerPlus, 5(1), $1-24$.

Charlton, R. (2008). Fundamentals of fluvial geomorphology. Londres: Ed. Routledge.

Chiu, Y., Chang, K., Chen, Y., Chao, J. y Lee, H. (2011). Estimation of soil erosion rates in a subtropical mountain watershed using 137Cs radionuclide. Natural Hazards, 59, 271-284.

de Oliveira, P., Sobrinho, T., Bicca, D. y Panachuki, E. (2011). Erosion risk mapping applied to environmental zoning. Water Resources Manage, 25, 1021-1036.

El Diario de Hoy. (1 de julio de 2011). Alertan alcaldes falta resolver que se hará con quienes viven de la extracción. El Diario de Hoy, p. 59.
Escobar F., Martínez, R. y Posada, M. (1986). Estudio geológico y geotécnico del río Las Cañas y sus problemas relacionados con la erosión, San Salvador, El Salvador (Tesis de licenciatura inédita). Universidad Centroamericana José Simeón Cañas, San Salvador, El Salvador.

Giménez, M. (2008). Metodología de cálculo del factor topográfico, LS, integrado en los modelos RUSLE Y USPED. Aplicación al arroyo del lugar, Guadalajara (España) (Tesis de doctorado inédita). Universidad Politécnica de Madrid, Madrid, España.

Griffiths, J. y Stokes M. (2008). Engineering geomorphological input to ground models: an approach based on Earth systems. Quarterly Journal of Engineering Geology and Hydrogeology, 41, 73-91.

Hernández, E. W. (2004). Características geotécnicas y vulcanológicas de las tefras de Tierra Blanca Joven de Ilopango, El Salvador (Tesis de maestría inédita). Universidad Politécnica de Madrid y en la Universidad Politécnica de El Salvador, El Salvador.

Hudson, N. (1997). Medición sobre el terreno de la erosión del suelo y de la escorrentía, Organización de las Naciones Unidas para la Agricultura y la Alimentación. Boletín de Suelos de la FAO, 68. Recuperado de http://www.fao.org/docrep/t0848s/ t0848s00.htm

James, L., Hodgson, M., Ghoshal, S. y Latiolais, M. (2012). Geomorphic change detection using historic maps and DEM differencing: The temporal dimension of geospatial analysis. Geomorphology, 137, 181-198. 
Jiang, L., Yao, Z., Liu, Z., Wu, S., Wang, R. y Wang, L. (2015). Estimation of soil erosion in some sections of Lower Jinsha River based on RUSLE. Natural Hazards, 76, 1831-1847.

Kheir, R., Cerdan, O. y Abdallah, C. (2006). Regional soil erosion risk mapping in Lebanon. Geomorphology, 82, 347-359.

Kim, J., Saunders, P. y Finn, J. (2005). Rapid assessment of soil erosion in the rio Lempa basin, Central America, using the Universal Soil Loss Equation and Geographic Information Systems. Environmental Management, 36(6), 872-885.

Kirkby, M. y Morgan, R. (1984). Erosión de suelos. México D. F.: Ed. LIMUSA,

Lee, S. (2004). Soil erosion assessment and its verification using the Universal Soil Loss Equation and Geographic Information System: a case study at Boun, Korea. Environmental Geology, 45, 457-465.

Martin-Fernández, L. y Martínez, M. (2011). An empirical approach to estimate soil erosion risk in Spain. Science of the Total Environment, 409, 3114-3123.

Marn, (2013). Atlas de la zonificación zmbiental, mapa de uso de suelos de municipios de Apopa, Tonacatepeque, San Martin, Delgado, Soyapango e Ilopango. Recuperado de http://www.marn.gob.sv/ directrices-para-la-zonificacion-ambiental-de-la-sub-region-metropolitana-desan-salvador-srmss/

Malik, I. (2008). Dating of small gully formation and establishing erosion rates in old gullies under forest by means of anatomical changes in exposed tree roots (Southern Poland). Geomorphology, 93, 421-436.

Molina, B., Pérez, G. y Vásquez, M. (2009). Caracterización geotécnica de las tefras Tierra Blanca Joven: unidad " $G$ " en la zona proximal y obras de protección (Tesis de licenciatura inédita). Universidad Centroamericana José Simeón Cañas, San Salvador, El Salvador.

Nigel, R. y Rughooputh, S. (2010). Mapping of monthly soil erosion risk of mainland Mauritius and its aggregation with delineated basins. Geomorphology, 114, 101114.

Perroy, L., Bookhagen, B., Asner, G. y Chadwick, O. (2010). Comparison of gully erosion estimates using airborne and ground-based LIDAR on Santa Cruz Island, California. Geomorphology, 118, 288-300.

Rolo, R., Bomer, J. J., Houghton, B. F., Vallance, J. W., Berdousis, P., Mavrommati, C. y Murphy, W. (2004). Geologic and engineering characterization of Tierra Blanca pyroclastic ash deposits. Geological Society of America, Special Paper, 375, 55-67.

Šebesta, J. Chavez, J. y Hernández, W. (2010). Cartografia y evaluación para estudiar los procesos erosivos en el Área Metropolitana de San Salvador (escala 1:25 000). San Salvador: OPAMSS-Embajada de Republica Checa en Costa Rica. Reporte Interno OPAMSS, Archivo del Servicio Geológico Checo.

Šebesta, J. y Chavez, J. (2011). Mapa geomorfológico de la sub-región del Área Metropolitana de San Salvador 
(escala 1:25 000). San Salvador: OPAMSS. Reporte Interno OPAMSS, Archivo del Servicio Geológico Checo.

Vergari, F. (2015). Assessing soil erosion hazard in a key badland area of Central Italy. Natural Hazards, 79, 71-95.

Vrieling, A. (2006). Satellite remote sensing for water erosion assessment: A review. Catena, 65, 2-18.

Vrieling, A., De Jong, S., Sterk, G. y Rodrigues, S. (2008). Timing of erosion and satellite data: a multi-resolution approach to soil erosion risk mapping. International Journal of Applied Earth Observation and Geoinformation, 10, 267-281.

Wischmeier, W. H. y Smith, D. D. (1978). Predicting rainfall erosion losses- a guide to conservation practice. Estados Unidos: Ed. U.S. Department of Agriculture, Agriculture Handbook No. 537.

Yang, S. y Zhu, Q. (2003). A model of intelligent interpreting soil erosion based on geographical knowledge. IGARSS 003 Proceedings, 4, 2468-2470 